\title{
A study of the morphology and effective density of externally mixed black carbon aerosols in ambient air using a size-resolved single-particle soot photometer (SP2)
}

\author{
Yunfei Wu${ }^{1}$, Yunjie Xia ${ }^{1,2}$, Rujin Huang ${ }^{3}$, Zhaoze Deng ${ }^{4}$, Ping Tian ${ }^{5}$, Xiangao Xia ${ }^{4}$, and Renjian Zhang ${ }^{1}$ \\ ${ }^{1}$ Key Laboratory of Regional Climate-Environment for Temperate East Asia (RCE-TEA), Institute of Atmospheric Physics, \\ Chinese Academy of Sciences, Beijing 100029, China \\ ${ }^{2}$ University of Chinese Academy of Sciences, Beijing 100049, China \\ ${ }^{3}$ Key Laboratory of Aerosol Chemistry and Physics, State Key Laboratory of Loess and Quaternary Geology, \\ Institute of Earth and Environment, Chinese Academy of Sciences, Xi' an 710061, China \\ ${ }^{4}$ Key Laboratory of Middle Atmosphere and Global Environment Observation (LAGEO), Institute of Atmospheric Physics, \\ Chinese Academy of Sciences, Beijing 100029, China \\ ${ }^{5}$ Beijing Weather Modification Office, Beijing 100089, China
}

Correspondence: Yunfei Wu (wuyf@mail.iap.ac.cn) and Renjian Zhang (zrj@mail.iap.ac.cn)

Received: 21 November 2018 - Discussion started: 10 December 2018

Revised: 11 July 2019 - Accepted: 23 July 2019 - Published: 12 August 2019

\begin{abstract}
The morphology and effective density of externally mixed black carbon (extBC) aerosols, important factors affecting the radiative forcing of black carbon, were studied using a tandem technique coupling a differential mobility analyzer (DMA) with a single-particle soot photometer (SP2). The study extended the mass-mobility relationship to large extBC particles with a mobility diameter $\left(d_{\text {mob }}\right)$ larger than $350 \mathrm{~nm}$, a size range seldom included in previous tandem measurements of $\mathrm{BC}$ aggregates in the atmosphere. The experiment was conducted at an urban site in Beijing during a 19 d winter period from 23 January to 10 February 2018. Ambient dry particles were selected by the DMA, and the size-resolved extBC particles were distinguished from particles with a thick coating (internally mixed) according to the time delay between the incandescence signal peak and the scattering peak detected by the SP2. The masses of the extBC particles were then quantified. The time differences between the DMA size selection and the SP2 measurement were processed previously. The normalized number size distributions were investigated at the prescribed $d_{\text {mob }}$ sizes in the range of $140-750 \mathrm{~nm}$ to provide the typical mass of extBC at each $d_{\text {mob }}$. On this basis, the mass-mobility relationship of the ambient extBC was established, inferring a mass-mobility scaling exponent $\left(D_{\mathrm{fm}}\right)$ (an important quantity for characterizing the morphology of fractal-like $\mathrm{BC}$ aggregates) with
\end{abstract}

a value of $2.34 \pm 0.03$ in the mobility range investigated in this study. This value is comparable with those of diesel exhaust particles, implying a predominant contribution of vehicle emissions to the ambient extBC in urban Beijing. Compared to the clean period, a higher $D_{\mathrm{fm}}$ value was observed in the polluted episode, indicating a more compact $\mathrm{BC}$ aggregate structure than that in the clean period. The effective densities ( $\left.\rho_{\text {eff }}\right)$ of the extBC in the same $d_{\text {mob }}$ range were also derived, with values gradually decreasing from $0.46 \mathrm{~g} \mathrm{~cm}^{-3}$ at $140 \mathrm{~nm}$ mobility to $0.14 \mathrm{~g} \mathrm{~cm}^{-3}$ at $750 \mathrm{~nm}$ mobility. The $\rho_{\text {eff }}$ values were slightly lower than those measured using the DMA-aerosol particle mass analyzer (APM) system. The difference in $\rho_{\text {eff }}$ values was likely due to the lower BC masses determined by the SP2 compared to those measured by the APM at the same mobility, since the SP2 measured the refractory $\mathrm{BC}(\mathrm{rBC})$ mass instead of the total mass of the $\mathrm{BC}$ aggregate, which consists of both $\mathrm{rBC}$ and a possible fraction of nonrefractory components measured by the APM. The $\rho_{\text {eff }}$ values in the $280-350 \mathrm{~nm} d_{\text {mob }}$ range were much closer to the values for soot aggregates reported in the literature. It might be related to the more compact structure of $\mathrm{BC}$ aggregates in this range, resulting from the reconstruction effect by volatile and/or semivolatile components in the atmosphere. The reconstruction effect might also result in a hiatus in the increased dynamic shape factor in the range of 
200-350 nm, which presented an overall increase from 2.16 to 2.93 in the $140-750 \mathrm{~nm} d_{\text {mob }}$ range.

\section{Introduction}

Black carbon (BC), a by-product of incomplete combustion, is the main light-absorbing component in atmospheric aerosols. $\mathrm{BC}$ can lead to positive radiative forcing second only to $\mathrm{CO}_{2}$ in magnitude and thus warming of the earth's atmosphere (IPCC, 2013). However, there remains a large amount of uncertainty regarding the radiative forcing induced by $\mathrm{BC}$ due to its complexity and variability in morphology, mixing state and hygroscopicity. Freshly emitted BC particles usually exhibit fractal-like aggregates composed of a number of primary carbon spherules (Park et al., 2004; Sorensen, 2011), which are generally hydrophobic. The condensation of organic and/or inorganic components leads to the collapse of fractal-like aggregates and, in turn, a compact structure of BC particles (Slowik et al., 2007; Zhang et al., 2008). Changes in the morphology of BC particles affect their optical properties. Encasement by organic and/or inorganic coatings also increases the absorption of BC particles through the lensing effect (Shiraiwa et al., 2010; Peng et al., 2016). In addition, water-soluble coatings increase the hydrophilic ability of BC particles (Zhang et al., 2008; McMeeking et al., 2011), indirectly affecting radiative forcing by affecting cloud processes.

Laboratory studies indicate that freshly emitted BC particles can become thickly coated within a few hours in the atmosphere (Pagels et al., 2009; Peng et al., 2016). Thus, many studies have focused on the optical properties and radiative forcing of thickly coated BC particles (Jacobson, 2001; Khalizov et al., 2009; Liu et al., 2017). However, in situ measurements have shown that a great number of uncoated and/or thinly coated BC particles exist in the ambient atmosphere, with a fraction even higher than that of aged $\mathrm{BC}$ particles (Schwarz et al., 2008). In general, thickly coated BC particles account for $<50 \%$ of the BC-containing particles in urban areas based on single-particle soot photometer (SP2) measurements (Huang et al., 2012; Wang et al., 2014; Wu et al., 2016). The existence of a large fraction of uncoated and/or thinly coated BC particles is likely due to continuous emission from combustion processes such as vehicle exhaust (Wang et al., 2017). Therefore, studies on the radiative forcing of $\mathrm{BC}$ particles without thick coatings are also essential, especially in urban areas. First, the morphologies and sizes of these quasi-bare $\mathrm{BC}$ particles, which are the essential quantities for calculating the optical properties of BC particles in numerical models, should be investigated (Scarnato et al., 2013; Bi et al., 2013).

The morphology of fractal-like BC aggregates is generally characterized by a quantity called the fractal dimension $\left(D_{\mathrm{f}}\right)$, which has been well documented in the review liter- ature (Sorensen, 2011). The ideal diffusion-limited cluster aggregation (DLCA), to which BC aggregates belong, has a $D_{\mathrm{f}}$ value of $1.78 \pm 0.1$. Recent studies have also reported a similar $D_{\mathrm{f}}$ value of $\sim 1.82$ for bare soot particles using transmission electron microscopy (TEM) analysis of aerosol samples collected in four different environments (Wang et al., 2017). A significant increase in the $D_{\mathrm{f}}$ was observed when the soot particles were partly coated or embedded. In the past 2 decades, the morphologies of $\mathrm{BC}$ aggregates have also been widely studied using tandem mobility techniques (Park et al., 2008). Measurements obtained using an impactor (e.g., an electrical low-pressure impactor, ELPI) or a particle mass analyzer (e.g., an aerosol particle mass analyzer, APM, or a centrifugal particle mass analyzer, CPMA) connected in tandem with a differential mobility analyzer (DMA) have revealed the relationship between particle mass and mobility (Park et al., 2003; Maricq and Xu, 2004; Olfert et al., 2007; Rissler et al., 2014; Sorensen, 2011; and associated references therein). The derived mass-mobility scaling exponents $\left(D_{\mathrm{fm}}\right)$, which have also been called fractal dimensions in some of these references, varied over a wide range of 2.2-2.8 for diesel exhaust particles. These values were inherently higher than the virtual $D_{\mathrm{f}}$, which is defined as the scaling exponents between the radius of gyration of an aggregate and the radius of primary spherules composing the aggregate, due to the improper interpretation of mobility measurements, as demonstrated in detail in Sorensen (2011). The $D_{\mathrm{f}}$ of diesel particles obtained using TEM is $\sim 1.75$, corresponding to a large $D_{\mathrm{fm}}$ value of $\sim 2.35$ based on the massmobility relationship (Park et al., 2004). The mobility sizedependent effective densities $\left(\rho_{\text {eff }}\right)$ of BC aggregates were also determined from the DMA-ELPI or DMA-APM (or CPMA) measurements, which were difficult to characterize using TEM techniques.

The previous tandem measurements generally provided the mass-mobility relationship of particles with a mobility diameter $\left(d_{\mathrm{mob}}\right)$ not exceeding $350 \mathrm{~nm}$ due to the system detection limit (Park et al., 2003; Maricq and Xu, 2004; Olfert et al., 2007; Rissler et al., 2014). A condensation particle counter (CPC) is connected next to the DMA-APM system to measure the number concentrations of mobility sizeselected particles at various APM voltages. The voltage is proportional to the particle mass, and the voltage resulting in the maximum concentration is in turn considered the typical voltage of the mass of particles with a prescribed mobility size. Because large particles (e.g., $d_{\mathrm{mob}}>350 \mathrm{~nm}$ ) are less abundant in the atmosphere than smaller particles, larger uncertainties exist in the DMA-APM-CPC measurements for the larger particles (Geller et al., 2006). Hence, the extrapolation of the mass-mobility relationship established on the basis of tandem measurements of small mobility diameters (e.g., $d_{\mathrm{mob}}<350 \mathrm{~nm}$ ) to large particles (e.g., $d_{\mathrm{mob}}>350 \mathrm{~nm}$ ) is insufficient.

The SP2 was developed on the basis of the laser-induced incandescence technique and provides advantages in the 
study of individual BC particle properties, including mass, size and mixing state. The SP2 determines the refractory $\mathrm{BC}(\mathrm{rBC})$ mass from particle to particle, thus providing the masses of $\mathrm{BC}$ aggregates throughout a wide size range (70$500 \mathrm{~nm}$ mass-equivalent diameter according to the manufacturer) with high sensitivity and accuracy (Schwarz et al., 2006). Recently, a tandem system consisting of an SP2 connected to a DMA was developed to study the properties of size-resolved $\mathrm{BC}$ aerosols in the atmosphere. The mass distributions and mixing states of the size-selected $\mathrm{BC}$ were investigated in northern India using a DMA-SP2 tandem system (Raatikainen et al., 2017). Coupling an SP2 with a volatility tandem DMA (VTDMA), the rBC core size distributions of internally mixed $\mathrm{BC}$ and those measured by the VTDMA were compared at the prescribed mobility size ranges. Subsequently, the morphology and effective density of the internally mixed BC particles were studied (Zhang et al., 2016). The hygroscopic properties of BC particles were studied using a hygroscopicity tandem DMA (HTDMA)SP2 coupling system (McMeeking et al., 2011; Liu et al., 2013). Few studies have been performed on the morphology and effective density of fractal-like $\mathrm{BC}$ aggregates that are not coated with other components, especially those in the ambient atmosphere, using DMA-SP2 measurements.

Using the DMA-SP2/CPC system, Gysel et al. (2012) revealed that the SP2 was unable to reliably detect BC particles from a PALAS spark discharge soot generator due to the lower detection limit of the SP2 for loosely packed agglomerates made up of small primary spherules $(\sim 5-10 \mathrm{~nm}$ in diameter). However, they also claimed that a well-aligned SP2 was expected to have a detection efficiency adequate to measure BC aggregates (e.g., diesel exhaust soot) in the atmosphere because these $\mathrm{BC}$ aggregates have larger primary spherules and substantially higher effective densities than the agglomerates made up of small primary spherules. Therefore, in this study, a DMA-SP2 tandem system was built to examine the mass-mobility relationship (from which the morphology and effective density were further derived) of uncoated $\mathrm{BC}$ aggregates, especially in the large particle size range (e.g., $d_{\text {mob }}>350 \mathrm{~nm}$ ), which has seldom been included in previous tandem measurements. Moreover, the uncoated $\mathrm{BC}$ aggregates were distinguished from the thickly coated BC particles using SP2, thus allowing the study of the massmobility relationship of ambient BC aggregates in different atmospheric environments. Previous DMA-ELPI or APM tandem measurements were mainly conducted in the laboratory or in the source environments (e.g., in a tunnel) where fresh $\mathrm{BC}$ aggregates were predominant.

Beijing, the capital of China, has suffered from severe air pollution issues in recent years. Studies have revealed that emissions from coal combustion and/or biomass burning for industry activities and residential heating have played a predominant role in particulate pollution in Beijing, especially during the polluted episodes (Zhang et al., 2013; Huang et al., 2014; Wu et al., 2017; Ma et al., 2017a, b). Thus, the variation in the mass-mobility relationship of uncoated BC aggregates was also compared for a polluted episode and a clean episode to examine the possible influence of a source change on the morphology of these BC aggregates. In addition, a better mobility size resolution (33 logarithmic size bins from 20 to $750 \mathrm{~nm}$ ) was set for our DMA-SP2 system than was used in previous similar studies, in which only a few mobility diameters in the range of $\sim 150-350 \mathrm{~nm}$ were selected (Zhang et al., 2016; Liu et al., 2013; McMeeking et al., 2011). Similar to the study presented by Raatikainen et al. (2017), the high size resolution is advantageous for calculating the $\mathrm{BC}$ mass and number size distribution in the polluted region in our future studies.

\section{Measurements}

\subsection{Experimental setup}

A tandem system comprising a size selection unit and a measurement section was built and deployed in an ambient experiment that was conducted on the roof of a building (approximately $8 \mathrm{~m}$ above the ground) on the campus of the Institute of Atmospheric Physics, Chinese Academy of Sciences (IAP, CAS) during the winter from 23 January to 10 February 2018 (19 $\mathrm{d}$ in total). Located in an urban area of Beijing, the site is a few hundred meters from two main roads and thus may be significantly affected by vehicle emissions. More information on the measurement site is described in previous studies (e.g., Wu et al., 2016, 2017).

As shown in Fig. 1, polydisperse aerosols in the sample air were drawn through the size selection unit (a model 3087 neutralizer, a model 3080 classifier and a model 3081 DMA, TSI Inc., Shoreview, MN, USA) to generate quasimonodisperse particles with a certain electrical $d_{\text {mob }}$. Before entering the system, the ambient air was dried by passing through a $30 \mathrm{~cm}$ Nafion dryer (model MD-700-12F-3, Perma Pure LLC, Toms River, NJ, USA). A vacuum pump was used to draw the dry sheath air (e.g., particle-free indoor air) opposite to the flow direction of the sample air to provide the appropriate vacuum degree required for the dryer. The size-selected particles were delivered to the measurement section for analysis by various methods, including an SP2 (Droplet Measurement Technologies, Boulder, CO, USA), a CPC (model 3776, TSI Inc., Shoreview, MN, USA) and two microaethalometers (model AE51, AethLabs, San Francisco, CA, USA). The operational flow rates were set to $0.1,0.3$ and $0.15 \mathrm{~L} \mathrm{~min}^{-1}$ (STP) for the SP2, CPC and two AE51s, respectively. The sheath flow rate was set to $3 \mathrm{~L} \mathrm{~min}^{-1}$, resulting in a ratio of sheath-to-sample flow rate of $4.3: 1$ for the DMA. Particles in the range of $15-750 \mathrm{~nm}$ in mobility diameter could be selected. The flow rate for each instrument was calibrated using a soap film flowmeter (model Gilian Gilibrator-2, Sensidyne, Petersburg, FL, USA) before the experiment to ensure the accuracy of the selected particle sizes 


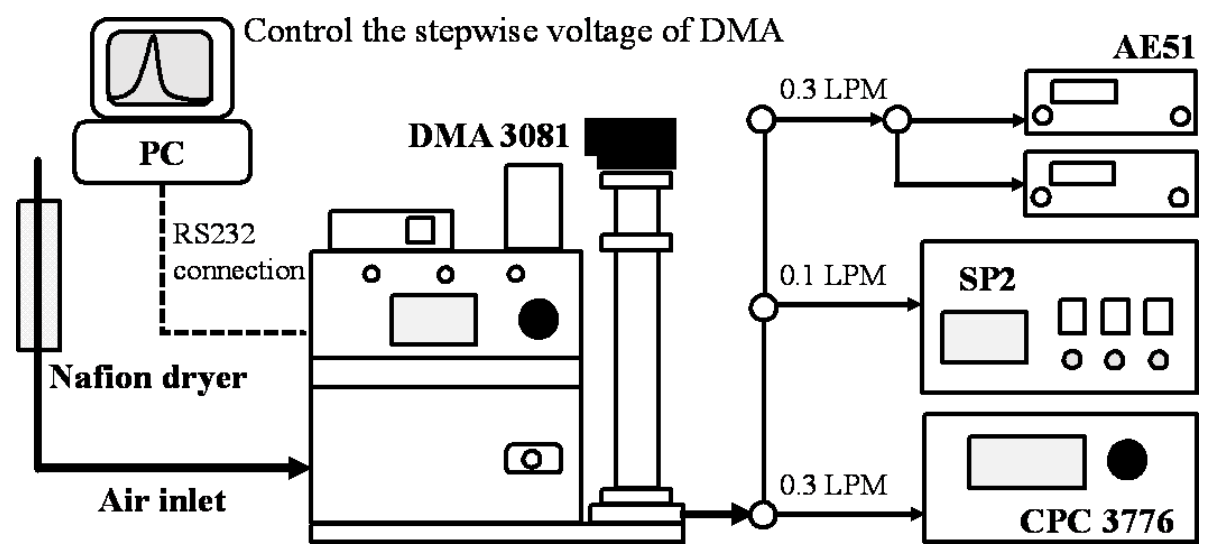

Figure 1. Schematic of the experimental setup for size-resolved measurements of black carbon.

and measurements. The scientific purpose of this experimental setup was to study the mixing states of size-selected BC particles, the mass and number size distribution of $\mathrm{BC}$, and the morphology and effective density of the uncoated BC aggregates that are discussed in the current study. Because only the DMA and SP2 were involved in the measurements presented in this study, the setting and operation of the two instruments are described and discussed in detail.

\subsection{Particle size selection}

The DMA was connected to an external computer on which a program was run to control the voltage of the DMA, i.e., the particle mobility diameter $\left(d_{\mathrm{mob}}\right)$. A total of $33 d_{\text {mob }}$ values were set in the program to cyclically control the particles selected by the DMA and gradually increase from 20 to $750 \mathrm{~nm}$ on the logarithmic scale. Stepwise size selection was repeated until the operator stopped the program. A short cycle lasting for $18 \mathrm{~s}$ for each of the 33 diameters and a long cycle lasting for $36 \mathrm{~s}$ for each size were set to alternately operate in this experiment (Fig. S1 in the Supplement). The purpose of these settings was to identify the time difference between the size selection and the subsequent measurement, as described in the following sections.

\subsection{Black carbon measurement}

The individual particulate $\mathrm{rBC}$ mass was measured by the SP2 according to the laser-induced incandescence signal when the particle passed through the intense Nd:YAG intracavity continuous laser beam (Schwardz et al., 2006) with a Gaussian distribution. The rBC mass in the SP2 detection range ( $\sim 0.3-250 \mathrm{fg}$ in this study, dependent on the laser intensity of a specific instrument) is proportional to the peak of the incandescence signal independent of the mixing state of the $\mathrm{BC}$ particles. If a $\mathrm{BC}$ particle is coated with nonrefractory components, the coating will evaporate before the $\mathrm{rBC}$ core incandesces, leading to a time lag between the peaks of incandescence and scattering signals that are synchronously detected by the SP2 (Moteki and Kondo, 2007). According to the frequency distribution of the time lag, there was a significant distinction between thickly coated (i.e., internally mixed) $\mathrm{BC}$ particles (intBC) and thinly coated or uncoated (i.e., externally mixed) $\mathrm{BC}$ particles (extBC) (Fig. S2) with a minimum frequency at $\sim 2 \mu$ s. BC-containing particles with delay times shorter than $2 \mu$ s were identified as extBC. The delay time threshold might vary slightly from one SP2 to another; for example, Zhang et al. (2016) reported a short time lag of $1.6 \mu \mathrm{s}$. However, the delay time threshold should be constant for a given instrument. In previous measurements using the same SP2 employed in this study, the critical delay time was maintained at $2 \mu$ s regardless of the ambient conditions, such as the pollution level (Wu et al., 2016, 2017). A fraction of BC-containing particles with thin or even moderate coatings might also be recognized as extBC using the time delay approach (Laborde et al., 2012). The effects of these thinly or even moderately coated BC particles are discussed in Sect. 3.2 by reducing the delay time threshold from 2 to 1.2 and $0.4 \mu \mathrm{s}$, respectively.

The scattering signal of a single particle synchronously detected by the SP2 can be used to estimate the optical size of the particle. The mixing state of a BC-containing particle can be deduced by comparing the optical size of the particle and the mass-equivalent size of the $\mathrm{rBC}$ core. Because the nonrefractory coating of a $\mathrm{BC}$-containing particle is evaporated due to the light absorption and heating of the $\mathrm{rBC}$ core when it passes through the laser beam, the scattering cross section of this particle, which is proportional to the scattering intensity at a given incident light intensity, is gradually decreased. To estimate the initial optical size of this particle, an approach called leading-edge-only (LEO) fitting was developed (Gao et al., 2007). A small fraction of the measured scattering signal in the initial stage before the particle is perturbed by the laser is employed in the LEO fitting to reconstruct the expected scattering distribution of the initial particle. In this method, the location of the leading edge in the beam is also required, which is determined from a two- 
element avalanche photodiode (APD) signal. Unfortunately, the notch in the two-element APD of our SP2 failed to fix in an adequate position (e.g., before the peak location of the laser beam) in this experiment. Thus, the optical size and the consequent coating thickness of the $\mathrm{BC}$-containing particle cannot be estimated. However, the coating thickness is not a crucial quantity in our current study on the morphology and density of uncoated BC aggregates. The coating thickness can provide a validation of our discrimination of extBC but should have little influence on our final analysis and the discussion presented in the following sections.

Before the experiment, the incandescence signal was calibrated using DMA-selected monodisperse Aquadag particles. The effective densities of the mobility size-selected Aquadag particles were determined based on the polynomial equation as a function of the $d_{\text {mob }}$ reported in Gysel et al. (2011). The incandescence signal is more sensitive to the Aquadag particles than to ambient BC particles because the Aquadag particle induces a higher incandescence signal peak (by a factor of $\sim 25 \%$ ) than fullerene soot or an ambient BC particle with the same mass (Laborde et al., 2012). Thus, the peak intensity of the incandescence signal was reduced by a factor of $25 \%$ when calculating the calibration coefficient. The calculated calibration factor, determined as the slope of the linear regression of $\mathrm{rBC}$ masses against the scaled peak heights of SP2's broadband incandescence signal, is consistent with the factor estimated using a single-point scaling procedure (Baumgardner et al., 2012). The same calibration was performed again after the experiment. The calibration factors varied little $(<3 \%)$, indicating the stability of the SP2 measurement during the entire experiment (Fig. S3). The uncertainty in the individual $\mathrm{rBC}$ mass determination is estimated to be $\sim 10 \%$ due to the uncertainties in the rBC mass calibration and the effective density of the calibration material. An additional uncertainty may also arise in the determination of extBC masses when the time delay approach is used to distinguish the mixing state of BC particles. The uncertainty will be further discussed in Sect. 3.2.

\section{Data processing}

\subsection{Identifying the time difference between the size selection and the SP2 measurement}

There exists a considerable difference between the time recorded by the size selection program and that recorded by the SP2, due to the time cost of the particles transmitting from the DMA to the SP2, as well as the system clock difference between the computer on which the size selection program runs and that for the SP2 data acquisition. As shown in Fig. S1, the SP2 measurement occurs significantly later than the size selection.

We have developed two methods to identify the time difference. The first method involves finding the time difference between the local peak in the particle number concentration (including both scattering and incandescence) detected by the SP2 and the beginning of the corresponding size selection cycle. During the experiment, stepwise size selection was cyclically performed to produce quasi-monodisperse particles with sizes gradually increasing from 20 to $750 \mathrm{~nm}$. Thus, at the beginning of each new cycle, the voltage of the DMA should first drop drastically from a high value to a low one to make the particle size decrease from 750 to $20 \mathrm{~nm}$. As a result, some particles with sizes in an efficiently detectable range of the SP2 ( 100-500 $\mathrm{nm})$ are measured during the descent period, producing a local peak in the number concentration. Because it takes only a few seconds for the descent, identifying the occurrence time of the local peak position based on the SP2 clock and the beginning time of the size selection based on the external computer clock provides the time difference for each cycle.

The other method involves checking the consistency of the number and/or mass size distributions between the shortduration cycle and long-duration cycle. Although the durations of each size in the short cycle and long cycle are different ( $18 \mathrm{~s}$ vs. $36 \mathrm{~s})$, the time difference between the size selection and the measurement should be uniform for adjacent short and long cycles. Setting an initial time difference and calculating the mean number and/or mass concentration of each particle size, the number and/or mass size distributions are obtained. Then, the correlation coefficients between the size distributions during short and long cycles are calculated. Changing the time difference gradually, we can obtain a set of correlation coefficients as functions of the time differences. The time difference resulting in the maximum correlation coefficient is considered the difference between the size selection and the measurement.

Since the detection efficiency of the SP2 decreases dramatically in the small particle range (Fig. S4), the size distributions of the SP2-detected particles are inadequate for further calculation of the correlation coefficients. Therefore, the former method was employed in the current study to identify the time difference between the size selection and the SP2 measurement. The latter method will be used to examine the time difference between the size selection and the AE51 and $\mathrm{CPC}$ measurements in our future study on the number and mass size distributions of $\mathrm{BC}$.

\subsection{Determination of the typical masses of extBC at prescribed mobility sizes}

Particles in a certain size range are selected by the DMA instead of absolutely monodisperse particles in a given mobility size due to the effect of the transfer function. In addition, larger particles with multiple charges are also selected. The frequency and number size distributions of extBC as a function of the mass-equivalent diameter of $\mathrm{rBC}\left(d_{\mathrm{me}}\right)$ at different mobility sizes are presented in Figs. S5 and S6, respectively. Note that the number size distribution has been normalized 


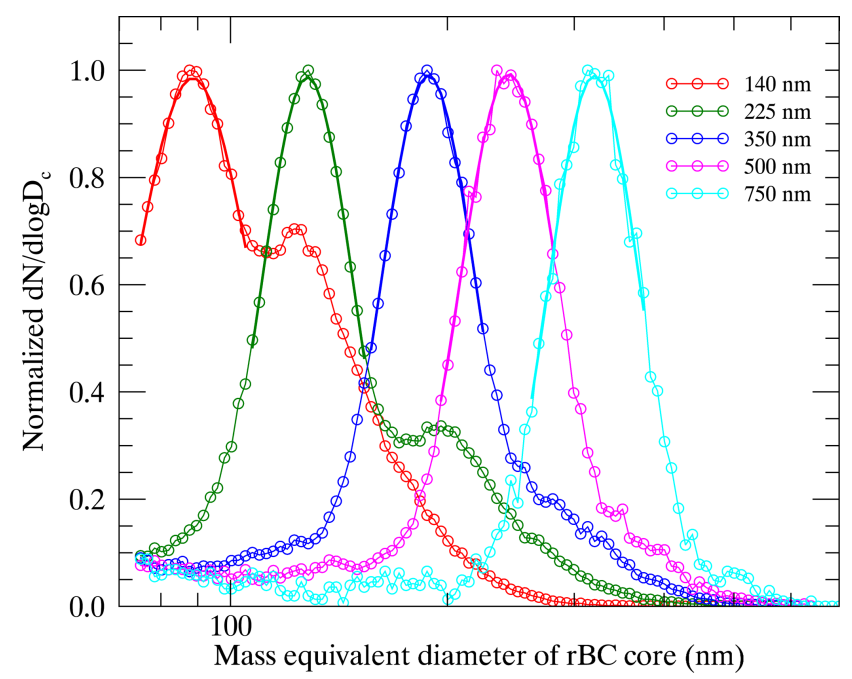

Figure 2. Campaign average number size distribution of the massequivalent diameter of the $\mathrm{rBC}$ core of extBC normalized by the peak value at five representative mobility diameters (140, 225, 350, 500 and $750 \mathrm{~nm}$ ) selected by the DMA. Lognormal fitting is performed for the major peak of each distribution.

by the peak value of the corresponding distribution. Since the frequency and number size distributions of extBC are quite insufficient at small particle sizes $\left(d_{\mathrm{me}}<70 \mathrm{~nm}\right)$ due to the low detection efficiency of the SP2 (Fig. S4), only the distributions with a $d_{\text {mob }}$ larger than $140 \mathrm{~nm}$ are presented. In the following study, we mainly address the morphology and effective density of extBC in the $140-750 \mathrm{~nm} d_{\text {mob }}$ range. The normalized number size distributions at five representative $d_{\text {mob }}$ values (i.e., $140,225,350,500$ and $750 \mathrm{~nm}$ ) are also shown in Fig. 2. The extBC particles with a considerable $d_{\text {me }}$ range were observed for a certain $d_{\text {mob }}$, indicating a wide transfer function of the DMA due to the relatively low ratio of sheath-to-sample flow $(4.3: 1)$. Multicharged particles also affected the size distribution, especially in the $d_{\text {mob }}$ range of 100-400 nm (Ning et al., 2013). As shown in Figs. S6 and 2, a minor peak is obviously observed in the right tail of the major peak at each size distribution for $d_{\text {mob }}$ values of $<350 \mathrm{~nm}$.

As mentioned above, a fraction of thinly and/or moderately coated $\mathrm{BC}$ particles might also be recognized as extBC according to the time delay between the SP2 incandescence and scattering signal peaks. These particles also have impacts on the size distribution of extBC for a given mobility size. A thinly coated $\mathrm{BC}$ particle can be expected to have a larger mass than a bare $\mathrm{BC}$ with the same mobility due to the restructuring of the thinly coated $\mathrm{BC}$ particle by coating materials. These thinly coated $\mathrm{BC}$ particles will increase the size distribution in the right tail when mixed with multicharged particles. It is currently difficult or even impossible to separate the effects of the thinly coated and multicharged particles based on the size distribution of extBC. To examine the possible effect of these thinly coated particles, we tightened the criterion of the delay time for the discrimination of extBC, gradually decreasing from $<2.0$ to $<1.2$ and $<0.4 \mu$ s. As shown in Figs. S5 and S6, a decrease in the delay time threshold results in a significant reduction in the data volume used in the analysis but has few effects on the major peak location of the distribution, which is used as the typical $d_{\mathrm{me}}$ of extBC for a given mobility size. The typical $d_{\text {me }}$ values, determined as the mode values of the lognormal function that are employed to fit the major peak of the size distribution at a certain mobility size, vary little with the delay time thresholds (Table S1 in the Supplement). The maximum discrepancy in the $d_{\mathrm{me}}$ is $<3 \%$ throughout the prescribed mobility size range in this study $(140-750 \mathrm{~nm})$. The change caused by the delay time threshold mainly appears in the right tail of the normalized number size distribution. Reducing the delay time threshold to $0.4 \mu$ s results in a significant decrease in the fraction of particles with a large $d_{\text {me }}$ compared to the 2.0 and $1.2 \mu$ s thresholds (Fig. S6). These large particles are likely attributed to thinly and/or even moderately coated BC particles whose structures are relatively more compact than the absolutely bare $\mathrm{BC}$ particles. Therefore, we propose that thinly and/or even moderately coated $\mathrm{BC}$ and multicharged particles should both have effects on the size distribution of extBC, mainly in its right tail, but have little influence on the typical $d_{\text {me }}$, which is considered the peak $d_{\text {me }}$ of the distribution for a given mobility size. The uncertainty in the typical $d_{\text {me }}$ due to the time delay approach that was utilized to distinguish the extBC is approximately $3 \%$ at a given $d_{\text {mob }}$, which is in turn $\sim 10 \%$ of the corresponding mass of extBC. Combining the uncertainty in the $\mathrm{rBC}$ mass determined by the SP2 $(\sim 10 \%)$, the total uncertainty in the determined mass of extBC should be $\sim 20 \%$ in the studied mobility range of 140-700 nm. To achieve an adequate data volume for the analysis, the results and discussion presented in the following sections are based on the database of extBC discriminated as $\mathrm{BC}$-containing particles with delay times of less than $2.0 \mu \mathrm{s}$, unless otherwise specified.

\subsection{Theoretical calculation of the morphology and effective density}

The structure of extBC, agglomerated by primary spherules with diameters of 20-60 nm (Alexander et al., 2008), can be characterized by its mass-mobility relationship, which is approximately expressed as a power-law relationship between the mass of the agglomerate particle $(m)$ and its mobility diameter $\left(d_{\mathrm{mob}}\right)$, expressed as

$m=k \cdot d_{\mathrm{mob}}^{D_{\mathrm{fm}}}$,

where the prefactor $k$ is a constant and $D_{\mathrm{fm}}$ is the massmobility scaling exponent, which was sometimes erroneously called the fractal dimension in previous studies (e.g., Park et al., 2003). This quantity corresponds well to the virtual $D_{\mathrm{f}}$ and represents the morphology of the BC aggregates 
(Sorensen, 2011). The $D_{\mathrm{fm}}$ value of a sphere is 3 . Thus, the morphology of a particle becomes increasingly closer to that of a sphere as the $D_{\mathrm{fm}}$ increases gradually to 3 .

The effective density ( $\left.\rho_{\text {eff }}\right)$ of the extBC particles is calculated as the ratio of the $\mathrm{BC}$ mass $(m)$ measured using the SP2 and the $\mathrm{BC}$ volume, which is based on the $d_{\text {mob }}$ selected by the DMA, expressed as

$\rho_{\mathrm{eff}}=\frac{6 m}{\pi d_{\mathrm{mob}}^{3}}$.

Combining Eqs. (1) and (2), $\rho_{\text {eff }}$ can also be expressed as a function of $d_{\mathrm{mob}}$,

$\rho_{\mathrm{eff}}=K \cdot d_{\mathrm{mob}}^{D_{\mathrm{fm}}-3}$,

where $K$ is a constant, corresponding to the prefactor $k$ in the mass-mobility relationship.

The dynamic shape factor is also calculated to indicate the morphology of the extBC particles. It is derived from the ratio of the slip-corrected mass-equivalent diameter $\left(d_{\mathrm{me}}\right)$ and $d_{\text {mob }}$, expressed as

$\chi=\frac{d_{\mathrm{mob}} \cdot C_{\mathrm{c}}\left(d_{\mathrm{me}}\right)}{d_{\mathrm{me}} \cdot C_{\mathrm{c}}\left(d_{\mathrm{mod}}\right)}$,

where $d_{\text {me }}$ is calculated from the BC mass $(m)$ by assuming the $\mathrm{BC}$ particle to be a compact sphere with a density of $1.8 \mathrm{~g} \mathrm{~cm}^{-3}$ (Taylor et al., 2015), and $C_{\mathrm{c}}$ is the Cunningham slip correction factor parameterized by particle diameter $(d)$

$C_{\mathrm{c}}(d)=1+\frac{2 \lambda}{d}\left[\alpha+\beta \exp \left(-\frac{\gamma \cdot d}{2 \lambda}\right)\right]$,

where $\lambda$ is the mean free path of the gas molecules, which is set to $65 \mathrm{~nm}$ in this study according to Zhang et al. (2016). The values of the three empirical parameters $\alpha, \beta$ and $\gamma$ are 1.257, 0.4 and 1.1, respectively (Eq. 9.34 on p. 407 in Seinfeld and Pandis, 2006).

\section{Results and discussion}

\subsection{Mass-mobility relationship of the ambient extBC}

A power-law relationship was applied to the $d_{\mathrm{mob}^{-}}$ determined extBC mass values, delivering a campaign average mass-mobility scaling exponent $\left(D_{\mathrm{fm}}\right)$ of the ambient extBC (Fig. 3). In the $d_{\text {mob }}$ range of $140-750 \mathrm{~nm}$, the fitted $D_{\mathrm{fm}}$ is 2.34 , with 1 standard deviation of 0.03 . The fitted $D_{\mathrm{fm}}$ is close to the lower limit of the $D_{\mathrm{fm}}$ values of diesel exhaust particles presented in the literature, indicating the dominant contribution of diesel exhaust to the extBC in our measurement site in urban Beijing. Depending on the fuel type, engine type and load, the $D_{\mathrm{fm}}$ of diesel exhaust particles measured by the DMA-APM or DMA-ELPI systems ranged between 2.22 and 2.84 (Olfert et al., 2007; Maricq

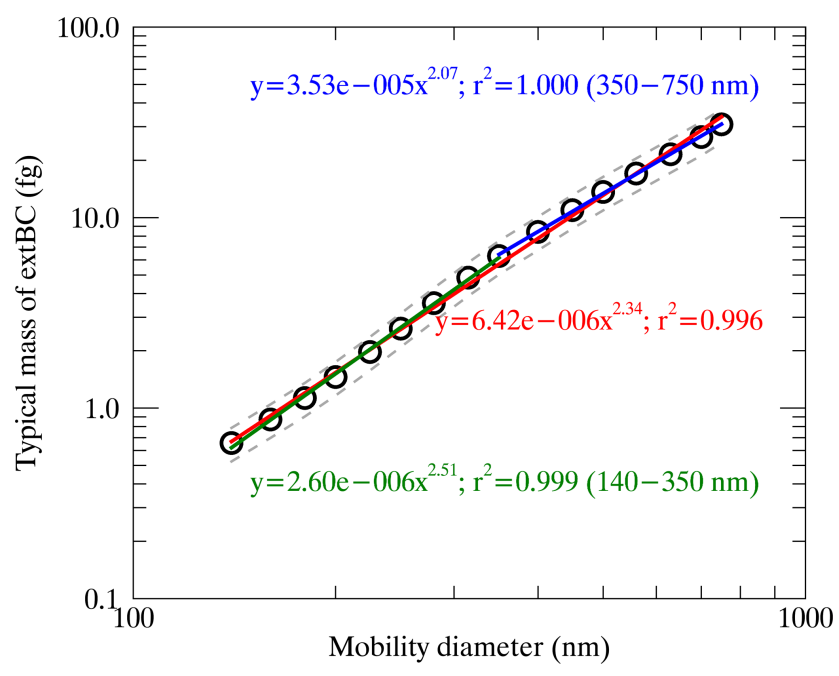

Figure 3. The mass of extBC particles as a function of the mobility diameter in the range of $140-750 \mathrm{~nm}$ (black circles), fitted by a power-law relationship (red line). The power-law functions piecewise fitted in the $140-350 \mathrm{~nm}$ mobility range (green line) and in the $350-750 \mathrm{~nm}$ mobility range (blue line) are overlaid. The dashed lines represent the uncertainties in the determined extBC masses.

and $\mathrm{Xu}, 2004$; Park et al., 2003, and references therein). The higher $D_{\mathrm{fm}}$ values in the literature are likely attributed to the higher fraction of volatile and/or semivolatile components (e.g., sulfate) in the diesel exhaust (Park et al., 2003; Olfert et al., 2007). The presence of these volatile and/or semivolatile components would result in a more compact structure of the particle, leading to a higher $D_{\mathrm{fm}}$ value for coated particles than for bare $\mathrm{BC}$ aggregate. Because the $\mathrm{rBC}$ mass instead of the whole particle mass of extBC was measured by the $\mathrm{SP} 2$, a relatively low $D_{\mathrm{fm}}$ value was expected and reasonable in this study. In addition, the relatively low $D_{\mathrm{fm}}$ value observed in urban Beijing also likely implies high fuel quality (e.g., low sulfur content) and efficient combustion in vehicle engines, which decrease the organic and/or inorganic fractions in diesel exhaust particles. The $D_{\mathrm{fm}}$ value for the ambient soot agglomerates measured with a DMA-APM system near a diesel-truck-dominated highway was 2.41 (Geller et al., 2006), slightly higher than the value in our study.

According to Sorensen (2011), the ideal fractal-like DLCA with a virtual $D_{\mathrm{f}}$ of approximately 1.78 should have an expected $D_{\mathrm{fm}} \approx 2.2$ in the slip flow regime in which the BC aggregates are generally observed. The slightly larger $D_{\mathrm{fm}}$ value of ambient extBC (2.34) in the current study might indicate a more compact structure than the ideal fractallike DLCA due to the reconstruction effect by other components in the atmosphere. The reconstruction effect appears to be more significant in the smaller particle range than in the larger particle range. The smaller $\mathrm{BC}$ particles are more likely to be coated by volatile and/or semivolatile materials, which will be discussed in detail in the next section. We piecewise fitted the mass-mobility relationship using the 
power-law function in the mobility ranges of $140-350$ and $350-750 \mathrm{~nm}$. A $D_{\mathrm{fm}}$ of $2.51 \pm 0.04$ that was obtained in the smaller mobility range $(140-350 \mathrm{~nm})$ was obviously larger than the fitted value in the whole size range (140-750 nm). In contrast, a much lower $D_{\mathrm{fm}}$ with a value of $2.07 \pm 0.02$ was observed in the larger mobility range $(350-750 \mathrm{~nm})$. These results indicate that the ambient extBC particles with larger mobility diameters were likely less influenced by the reconstruction effect than those with smaller mobility diameters.

The variation in the morphology of extBC was further examined by comparing the mass-mobility relationship in a polluted episode with that in a subsequent clean period. As shown in Fig. S7, a polluted episode rapidly formed at 14:00 (local time, if not specified) on 26 January and lasted $1.5 \mathrm{~d}$ to $00: 00$ on 28 January 2018 . The mean $\mathrm{PM}_{2.5}$ mass concentration was $72.1 \pm 23.1 \mathrm{\mu g} \mathrm{m}^{-3}$ in this polluted episode, 3 times the campaign average value $\left(23.0 \pm 26.7 \mu \mathrm{g} \mathrm{m}^{-3}\right)$. The $D_{\mathrm{fm}}$ value was $2.42 \pm 0.09$ in the polluted episode, higher than that $(2.33 \pm 0.06)$ observed in the subsequent clean period from 01:00 on 28 January to 18:00 on 31 January 2018, during which the average $\mathrm{PM}_{2.5}$ concentration was merely $8.9 \pm 2.7 \mu \mathrm{g} \mathrm{m}^{-3}$ (Fig. S8). The higher $D_{\mathrm{fm}}$ in the polluted episode is mainly due to the increase in the masses of extBC at large mobility sizes (e.g., $d_{\mathrm{mob}}>250$ ). As shown in Table 1 , the typical masses of extBC in the $280-700 \mathrm{~nm} d_{\text {mob }}$ range in the polluted episode are $\sim 7 \%-13 \%$ larger than those in the clean period. Although the differences might result from the uncertainty $(\sim 20 \%)$ in the mass determination of extBC, the commonly larger extBC masses (in the $280-700 \mathrm{~nm} d_{\text {mob }}$ range) to some degree still imply a possibly more compact structure of extBC aggregates in the polluted episode, which might relate to changes in the dominant sources and the ambient environment. Previous studies have revealed that regionally transported pollutants emitted from coal combustion and/or biomass burning played an important or even predominant role in polluted episodes in Beijing (Wu et al., 2017; Ma et al., 2017a). Thus, a considerable fraction of extBC aggregates from these sources is likely to coexist with the local vehicle-emitted $\mathrm{BC}$ aggregates in the polluted episode, even though the proportion of extBC in the total BC-containing particles decreased (Fig. S9). These transported $\mathrm{BC}$ aggregates originating from coal combustion and/or biomass burning might have a more compact structure than those from vehicle exhaust due to the differences in the combustion environments and efficiencies. In addition, the $\mathrm{BC}$ aggregates might also become more compact due to the reconstruction effect by the volatile and/or semivolatile components, which are generally abundant in polluted episodes. Both possible factors are likely to result in the larger $D_{\mathrm{fm}}$ values in the polluted episode.

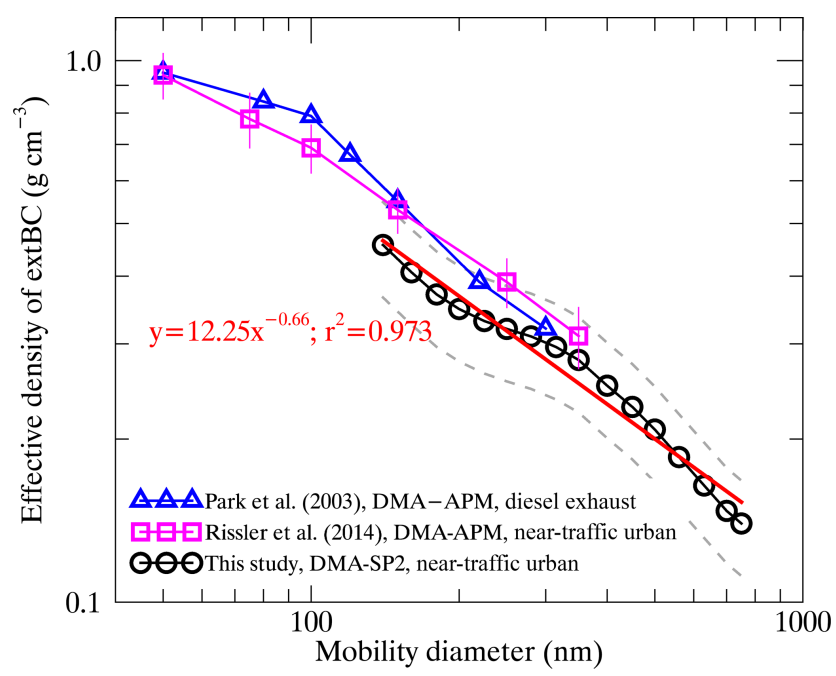

Figure 4. The effective density ( $\left.\rho_{\text {eff }}\right)$ of the extBC particles as a function of the mobility diameter $\left(d_{\text {mob }}\right)$ (black circles). The red line represents the power-law fitting of $\rho_{\text {eff }}$ versus $d_{\text {mob }}$. The variations in $\rho_{\text {eff }}$ with $d_{\text {mob }}$ measured for the soot agglomerates from diesel exhaust (Park et al., 2003) and near-traffic urban environments (Rissler et al., 2014) are also presented as blue triangles and red squares, respectively. The dashed lines represent the uncertainties in the determined $\rho_{\text {eff }}$.

\subsection{Size-resolved effective densities of the ambient extBC}

In contrast to the mass of extBC $(m)$, the effective density of the extBC particles $\left(\rho_{\text {eff }}\right)$ showed a significant decreasing trend as the $d_{\mathrm{mob}}$ increased from 140 to $750 \mathrm{~nm}$ (Fig. 4 and Table 1). The highest $\rho_{\text {eff }}$ of $0.46 \mathrm{~g} \mathrm{~cm}^{-3}$ was observed in the $140 \mathrm{~nm} d_{\text {mob }}$, likely because the BC aggregates at the smallest size are made up of the fewest primary spherules. When the $d_{\text {mob }}$ increased to $750 \mathrm{~nm}, \rho_{\text {eff }}$ decreased to as low as $0.14 \mathrm{~g} \mathrm{~cm}^{-3}$, approximately one-third of that at $140 \mathrm{~nm}$. The very low $\rho_{\text {eff }}$ values agree well with the fractal-like nature of the extBC particles.

The $\rho_{\text {eff }}$ values obtained by the DMA-SP2 measurements are close to those of the lower limits of diesel exhaust particles measured by the DMA-APM (or CPMA) or DMAELPI systems. Park et al. (2003) reported a decrease in the $\rho_{\text {eff }}$ of diesel exhaust particles under a moderate $(50 \%)$ engine load from 0.95 to $0.32 \mathrm{~g} \mathrm{~cm}^{-3}$ as the mobility diameter increased from 50 to $300 \mathrm{~nm}$ (Fig. 4). The $\rho_{\text {eff }}$ values presented in Park et al. (2003) are approximately 1.25, 1.18 and 1.05 times those in our study at $\sim 150,220$ and $300 \mathrm{~nm}$ in mobility diameter, respectively. The differences in $\rho_{\text {eff }}$ values between our study and the literature are generally within the uncertainty $(\sim 20 \%)$ in the mass determination of extBC at prescribed mobility sizes. However, the commonly lower $\rho_{\text {eff }}$ values are also likely due to the techniques used to determine the mass of BC aggregates. Some previous studies on the $\rho_{\text {eff }}$ of diesel exhaust particles using the DMA-APM or DMA- 
Table 1. The typical mass-equivalent diameters $\left(d_{\text {me }}\right)$ and corresponding masses of extBC for different mobility sizes $\left(d_{\text {mob }}\right)$ selected by the DMA in the whole campaign, in a polluted episode and in a clean period. The effective densities $\left(\rho_{\text {eff }}\right)$ and dynamic shape factors $(\chi)$ at the $d_{\text {mob }}$ selected by the DMA throughout the whole campaign are also presented.

\begin{tabular}{|c|c|c|c|c|c|c|c|c|}
\hline \multirow[t]{2}{*}{$d_{\text {mob }}(\mathrm{nm})$} & \multicolumn{3}{|c|}{$d_{\mathrm{me}}(\mathrm{nm})$} & \multicolumn{3}{|c|}{ Mass (fg) } & \multirow[t]{2}{*}{$\rho_{\text {eff }}\left(\mathrm{g} \mathrm{cm}^{-3}\right)$} & \multirow[t]{2}{*}{$\chi$} \\
\hline & Total & Polluted & Clean & Total & Polluted & Clean & & \\
\hline 140 & 88.8 & 87.2 & 88.5 & 0.66 & 0.63 & 0.65 & 0.46 & 2.16 \\
\hline 160 & 97.5 & 96.9 & 98.1 & 0.87 & 0.86 & 0.89 & 0.41 & 2.27 \\
\hline 180 & 106.2 & 106.1 & 107.0 & 1.13 & 1.13 & 1.15 & 0.37 & 2.35 \\
\hline 200 & 115.6 & 116.1 & 115.5 & 1.46 & 1.48 & 1.45 & 0.35 & 2.40 \\
\hline 225 & 127.9 & 128.6 & 128.4 & 1.97 & 2.01 & 1.99 & 0.33 & 2.41 \\
\hline 250 & 140.5 & 142.2 & 141.0 & 2.62 & 2.71 & 2.64 & 0.32 & 2.41 \\
\hline 280 & 155.8 & 158.0 & 154.4 & 3.56 & 3.72 & 3.47 & 0.31 & 2.41 \\
\hline 315 & 172.6 & 174.8 & 170.6 & 4.85 & 5.04 & 4.68 & 0.30 & 2.40 \\
\hline 350 & 188.2 & 191.8 & 185.9 & 6.28 & 6.65 & 6.05 & 0.28 & 2.41 \\
\hline 400 & 207.4 & 213.7 & 207.4 & 8.41 & 9.20 & 8.41 & 0.25 & 2.43 \\
\hline 450 & 226.4 & 232.3 & 225.9 & 10.94 & 11.81 & 10.87 & 0.23 & 2.50 \\
\hline 500 & 243.8 & 251.4 & 242.2 & 13.65 & 14.98 & 13.39 & 0.21 & 2.62 \\
\hline 560 & 262.6 & 271.1 & 260.1 & 17.06 & 18.77 & 16.58 & 0.19 & 2.71 \\
\hline 630 & 283.2 & 293.5 & 282.5 & 21.42 & 23.83 & 21.25 & 0.16 & 2.81 \\
\hline 700 & 305.1 & 312.7 & 305.0 & 26.76 & 28.83 & 26.73 & 0.15 & 2.89 \\
\hline 750 & 319.6 & 328.8 & 323.5 & 30.76 & 33.49 & 31.92 & 0.14 & 2.93 \\
\hline
\end{tabular}

ELPI tandem measurements also showed a slightly larger $\rho_{\text {eff }}$ throughout the comparable mobility ranges (e.g., $\sim 150$ $350 \mathrm{~nm}$ ) than that measured in this study (Maricq and $\mathrm{Xu}$, 2004; Olfert et al., 2007). The masses of the bare BC particles were determined by the laser-induced incandescence technique of the SP2. In a previous tandem system, the APM (or CPMA) or ELPI was utilized to determine the typical mass of $\mathrm{BC}$ aggregates at a given mobility, and the $\mathrm{BC}$ aggregates are likely composed of a fraction of volatile and/or semivolatile components in addition to the bare primary particles. These volatile and/or semivolatile components increase the mass of the whole particle, resulting in a larger $\rho_{\text {eff }}$ value for a certain mobility causing a compact structure of the BC aggregate. For example, Olfert et al. (2007) found that the $\rho_{\text {eff }}$ of diesel exhaust particles coated with minor sulfate and water contents ( $\sim 2 \%$ of the total particle mass) was $\sim 0.4 \mathrm{~g} \mathrm{~cm}^{-3}$ at $299 \mathrm{~nm}$, only slightly larger than the value of diesel exhaust particles $\left(0.32 \mathrm{~g} \mathrm{~cm}^{-3}\right)$ measured in Park et al. (2003) and that of extBC in the urban atmosphere $\left(0.31 \mathrm{~g} \mathrm{~cm}^{-3}\right)$ in our study at the same mobility size. However, the $\rho_{\text {eff }}$ value increased significantly to $\sim 0.71 \mathrm{~g} \mathrm{~cm}^{-3}$ at a relatively high engine load of $40 \%$ due to the high sulfate levels $(\sim 30 \%$ of the total particle mass) in the diesel exhaust particles (Olfert et al., 2007).

The $\rho_{\text {eff }}$ values of ambient soot aggregates also showed a similar decreasing trend with increasing $d_{\text {mob }}$ based on the DMA-APM system (Geller et al., 2006; Rissler et al., 2014). Rissler et al. (2014) showed a decrease in the average $\rho_{\text {eff }}$ of BC aggregates from 0.94 to $0.31 \mathrm{~g} \mathrm{~cm}^{-3}$ in the near-traffic urban environment as the $d_{\text {mob }}$ increased from 50 to $350 \mathrm{~nm}$ (Fig. 4), similar to that of the freshly emit- ted diesel exhaust particles presented in Park et al. (2003). However, based on the same method, the $\rho_{\text {eff }}$ values of the ambient $\mathrm{BC}$ aggregates that mostly originated from diesel exhaust (Geller et al., 2006) are substantially different from those presented in Rissler et al. (2014), especially in the large particle size range. The $\rho_{\text {eff }}$ at $\sim 350 \mathrm{~nm}$ was $0.17 \mathrm{~g} \mathrm{~cm}^{-3}$ in Geller et al. (2006), approximately half of the value presented in Rissler et al. (2014). The reason for the discrepancy might be related to the large measurement uncertainties of the DMA-APM system for large particles, e.g., with $d_{\text {mob }}$ sizes greater than $300 \mathrm{~nm}$, since these large particles are less abundant in the ambient atmosphere (Geller et al., 2006). Compared to the results presented in Rissler et al. (2014), the $\rho_{\text {eff }}$ values of ambient extBC aggregates in our study are slightly lower, e.g., by $\sim 17 \%, \sim 18 \%$ and $\sim 6 \%$ for $d_{\text {mob }}$ values of 150,250 and $350 \mathrm{~nm}$, respectively. The relatively higher $\rho_{\text {eff }}$ values are also likely attributed to the effects of volatile and/or semivolatile components in the soot aggregates. Rissler et al. (2014) found that the residual mass fraction of volatile and/or semivolatile materials in the soot aggregates was $\sim 10 \%$, even when the sample air was heated to $300^{\circ} \mathrm{C}$ before entering the system for measurement.

It is interesting to note that the $\rho_{\text {eff }}$ values appear to be closer to the values presented in the literature using the DMA-APM measurements in the $280-350 \mathrm{~nm} d_{\text {mob }}$ range (Fig. 4). As shown in Fig. 3, larger typical masses of extBC in this range are also observed beyond the logarithmic scaled linear curve that is fitted to the mass-mobility relationship. The relatively larger masses and $\rho_{\text {eff }}$ values might imply a more compact structure of extBC aggregates in this range, which likely results from the reconstruction effect by the 


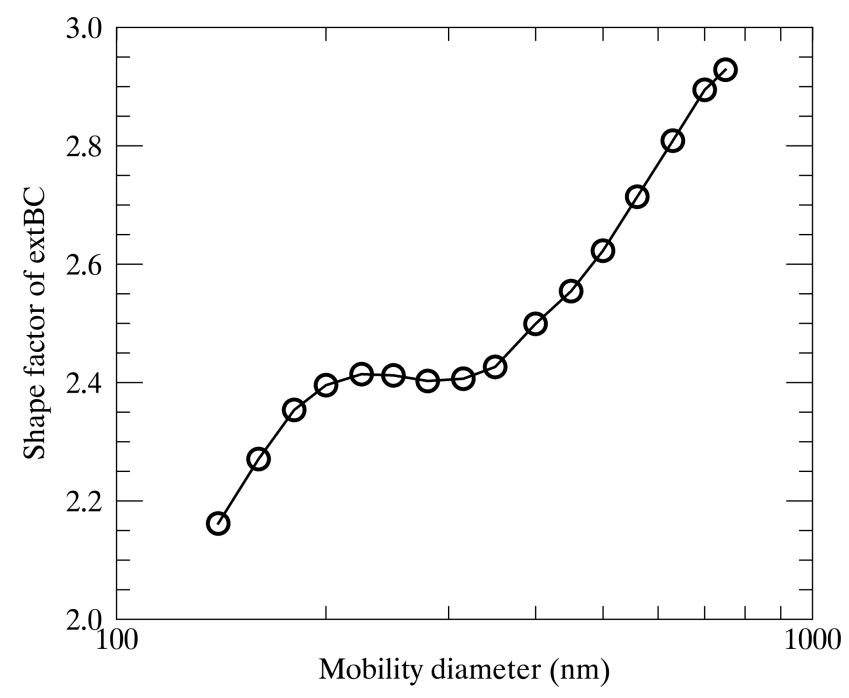

Figure 5. The dynamic shape factor of the extBC particles as a function of the mobility diameter in the range of $140-750 \mathrm{~nm}$.

ambient volatile and/or semivolatile components. As shown in Fig. S9, the size-resolved number fractions of extBC exhibit a minimum in the $280-350 \mathrm{~nm} d_{\text {mob }}$ range, regardless of whether they are associated with the polluted episode or the clean period. This finding indicates that particles in this mobility range are more likely to be thickly coated by other components than are particles in the smaller or larger mobility ranges. Zhang et al. (2016) also observed an increased coating thickness of the BC-containing particles in the mobility range of $200-350 \mathrm{~nm}$ (Table 1 in the literature) using the VTDMA-SP2 measurement at a suburban site $\sim 70 \mathrm{~km}$ away from our observation site, although the variation in the coating thickness in the larger mobility range was not investigated. Notably, the number fraction of extBC at each mobility size presented in Fig. S9 is roughly calculated as the ratio of the extBC number concentration to the sum of extBC and intBC, in which the multiply charged effects were not corrected. Although the extBC particles without coatings and/or with thin coatings are the focus of the current study, the higher fraction of thickly coated BC particles in the 280$350 \mathrm{~nm} d_{\text {mob }}$ range implies a higher possibility that these extBC particles in the same range were affected by volatile and/or semivolatile materials in the atmosphere, in turn resulting in a more compact structure of these $\mathrm{BC}$ aggregates. Further detailed studies of the size distribution of $\mathrm{BC}$ (including extBC, intBC and both) and non-BC particles based on the combined measurements of SP2 and CPC are needed in our further work to reveal the potential mechanism for this phenomenon.

Although the $\rho_{\text {eff }}$ of extBC at small sizes $\left(d_{\mathrm{mob}}<140 \mathrm{~nm}\right)$ cannot be determined due to the lower limit of the DMASP2 system, we extended the $\rho_{\text {eff }}$ of extBC to a large size range $\left(350<d_{\mathrm{mob}}<750 \mathrm{~nm}\right)$, which was barely investigated in previous studies using tandem measurements. A continu- ous decrease in $\rho_{\text {eff }}$ with increasing $d_{\text {mob }}$ was observed even in the large size range between 350 and $750 \mathrm{~nm}$ (Fig. 4). It is reasonable to infer that the structure of the extBC particles becomes looser when the fractal-like aggregates built up by the primary spherules increase.

\subsection{Dynamic shape factors of the ambient extBC}

Due to their fractal-like structures, the extBC particles generally have large dynamic shape factors $(\chi)$ with values in the range of 2.16 to 2.93 (Table 1), much larger than those of intBC with an average value of $\sim 1.2$ (Zhang et al., 2016). The $\chi$ value declined exponentially as a function of coating thickness of BC-containing particles (Zhang et al., 2016). In contrast to the decrease in $\rho_{\text {eff }}$, the $\chi$ values of extBC generally increase as $d_{\text {mob }}$ increases from 140 to $750 \mathrm{~nm}$ (Fig. 5). The extBC particles $750 \mathrm{~nm}$ in mobility diameter have a mean $\chi$ value of 2.93, approximately 1.36 times that for $140 \mathrm{~nm} d_{\text {mob }}$ particles (Table 1). The larger particles have looser structures, resulting in higher $\chi$ values. However, the $\chi$ values appear to vary slightly in a narrow range between 2.40 and 2.41 in the size range of 200 to $350 \mathrm{~nm}$ (Fig. 5). The hiatus in the gradual increase in $\chi$ is also likely related to the more compact structure of extBC particles in the 280 $350 \mathrm{~nm}$ mobility range, which has been discussed in detail in the previous sections.

\section{Conclusions}

The DMA-SP2 system was established to study the morphology and effective density of the ambient extBC particles, especially in the larger mobility size range, i.e., $350<d_{\mathrm{mob}}<750 \mathrm{~nm}$, which was seldom investigated in previous tandem measurements. Quasi-monodisperse particles in the $d_{\text {mob }}$ range of $20-750 \mathrm{~nm}$ were stepwise selected using the DMA and then delivered to the SP2 for $\mathrm{rBC}$ mass measurement and mixing state discrimination. The time difference between the size selection and the SP2 measurement was previously processed using the local peak approach. The normalized number size distribution of extBC, distinguished as having a delay time between the incandescence signal peak and the scattering peak detected by the SP2 of less than $2 \mu \mathrm{s}$, as a function of $d_{\mathrm{me}}$ was investigated at each prescribed mobility size in the range of $140-750 \mathrm{~nm}$. The size distributions at smaller mobility sizes were not presented due to the lower limit of the $\mathrm{rBC}$ mass determined using the SP2. The peak $d_{\text {me }}$, calculated as the mode value of a lognormal function fitted to the major peak of the size distribution, was determined as the typical $d_{\text {me }}$ value at each mobility size. Consequently, the typical mass of extBC at each mobility size was identified. Reducing the time delay threshold employed to discriminate the extBC had few effects on the determined masses of extBC, implying the reliability of our study for extBC particles. The uncertainty in the deter- 
mined extBC masses was $\sim 20 \%$, based on a combination of the uncertainty in the SP2-measured $\mathrm{rBC}$ mass and the uncertainty related to the time delay approach. On this basis, the mass-mobility relationship of ambient extBC in urban Beijing was investigated. The campaign-average $D_{\mathrm{fm}}$ value was estimated to be $2.34 \pm 0.03$ by fitting the derived extBC masses as a power-law function of $d_{\mathrm{mob}}$ in the range of 140 $750 \mathrm{~nm}$, close to the lower-limit $D_{\mathrm{fm}}$ value of diesel exhaust particles. A relatively larger $D_{\mathrm{f}}$ value was observed in the polluted episode than in the clean period $(2.42 \pm 0.09$ vs. $2.33 \pm 0.06$ ), implying a more compact structure of $\mathrm{BC}$ aggregates in the polluted episode.

A decrease in $\rho_{\text {eff }}$ with increasing $d_{\text {mob }}$ was observed, with the $\rho_{\text {eff }}$ value decreasing from $0.46 \mathrm{~g} \mathrm{~cm}^{-3}$ at a $d_{\text {mob }}$ value of $140 \mathrm{~nm}$ to $0.14 \mathrm{~g} \mathrm{~cm}^{-3}$ at $700 \mathrm{~nm}$. The $\rho_{\text {eff }}$ values derived using the DMA-SP2 measurement were slightly lower than those based on the DMA-APM measurement. This difference was most likely due to the bias in the extBC mass determination using the SP2 and APM techniques. The pure $\mathrm{rBC}$ mass determined using the SP2 in this study was generally lower than the total mass of the $\mathrm{BC}$ aggregate, which comprises both $\mathrm{rBC}$ and a possible fraction of nonrefractory components. The $\rho_{\text {eff }}$ values in the $280-350 \mathrm{~nm}$ mobility range appeared to be much closer to the values for soot aggregates reported in the literature by using the DMAAPM tandem measurement. This finding might be related to the more compact structure of $\mathrm{BC}$ aggregates in this range, which was likely influenced by the reconstruction effect of volatile and/or semivolatile components in the atmosphere. The reconstruction effect might also result in a hiatus in the gradually increased $\chi$ value in the range of $200-350 \mathrm{~nm}$. Large $\chi$ values generally increased from 2.16 to 2.93 with increasing $d_{\mathrm{mob}}$, further implying the high fractal structure of extBC particles.

Data availability. Data used in this study are available from YunfeiWu (wuyf@mail.iap.ac.cn).

Supplement. The supplement related to this article is available online at: https://doi.org/10.5194/amt-12-4347-2019-supplement.

Author contributions. RZ led and designed the study; YW designed the study, set up the experiment, analyzed the data, and wrote and drafted the paper. YX and PT collected the field data and contributed to data analysis; ZD provided the size selection procedure and contributed to data analysis; RH and XX finalized the paper. All coauthors provided comments on the paper.
Financial support. This research has been supported by the National Key Research and Development Program of China (grant nos. 2017YFC0209601 and 2017YFC0212701) and the National Natural Science Foundation of China (grant nos. 41575150, 41775155, 91644217, and 91644219).

Review statement. This paper was edited by Paolo Laj and reviewed by two anonymous referees.

\section{References}

Alexander, D. T., Crozier, P. A., and Anderson, J. R.: Brown carbon spheres in East Asian outflow and their optical properties, Science, 321, 833-836, https://doi.org/10.1126/science.1155296, 2008.

Baumgardner, D., Popovicheva, O., Allan, J., Bernardoni, V., Cao, J., Cavalli, F., Cozic, J., Diapouli, E., Eleftheriadis, K., Genberg, P. J., Gonzalez, C., Gysel, M., John, A., Kirchstetter, T. W., Kuhlbusch, T. A. J., Laborde, M., Lack, D., Müller, T., Niessner, R., Petzold, A., Piazzalunga, A., Putaud, J. P., Schwarz, J., Sheridan, P., Subramanian, R., Swietlicki, E., Valli, G., Vecchi, R., and Viana, M.: Soot reference materials for instrument calibration and intercomparisons: a workshop summary with recommendations, Atmos. Meas. Tech., 5, 1869-1887, https://doi.org/10.5194/amt-5-1869-2012, 2012.

Bi, L., Yang, P., Kattawar, G. W., and Mishchenko, M. I.: Efficient implementation of the invariant imbedding T-matrix method and the separation of variables method applied to large nonspherical inhomogeneous particles, J. Quant. Spectrosc. Ra., 116, 169183, https://doi.org/10.1016/j.jqsrt.2012.11.014, 2013.

Huang, R. J., Zhang, Y. L., Bozzetti, C., Ho, K.-F., Cao, J. J., Han, Y. M., Daellenbach, K. R., Slowik, J. G., Platt, S. M., Canonaco, F., Zotter, P., Wolf, R., Pieber, S. M., Bruns, E. A., Crippa, M., Ciarelli, G., Piazzalunga, A., Schwikowski, M., Abbaszade, G., Schnelle-Kreis, J., Zimmermann, R., An, Z. S., Szidat, S., Baltensperger, U., El Haddad, I., and Prévôt, A. S. H.: High secondary aerosol contribution to particulate pollution during haze events in China, Nature, 514, 218-222, https://doi.org/10.1038/nature13774, 2014.

Huang, X. F., Sun, T. L., Zeng, L. W., Yu, G. H., and Luan, S. J.: Black carbon aerosol characterization in a coastal city in South China using a single particle soot photometer, Atmos. Environ., 51, 21-28, https://doi.org/10.1016/j.atmosenv.2012.01.056, 2012.

Gao, R. S., Schwarz, J. P., Kelly, K. K., Fahey, D. W., Watts, L. A., Thompson, T. L., Spackman, J. R., Slowik, J. G., Cross, E. S., Han, J.-H., Davidovits, P., Onasch, T. B., and Worsnop, D. R.: A novel method for estimating lightscattering properties of soot aerosols using a modified singleparticle soot photometer, Aerosol Sci. Technol., 41, 125-135, https://doi.org/10.1080/02786820601118398, 2007. of interest. 
Geller, M., Biswas, S., and Sioutas, C.: Determination of particle effective density in urban environments with a differential mobility analyzer and aerosol particle mass analyzer, Aerosol Sci. Technol., 40, 709-723, https://doi.org/10.1080/02786820600803925, 2006.

Gysel, M., Laborde, M., Olfert, J. S., Subramanian, R., and Gröhn, A. J.: Effective density of Aquadag and fullerene soot black carbon reference materials used for SP2 calibration, Atmos. Meas. Tech., 4, 2851-2858, https://doi.org/10.5194/amt-4-2851-2011, 2011.

Gysel, M., Laborde, M., Mensah, A. A., Corbin, J. C., Keller, A., Kim, J., Petzold, A., and Sierau, B.: Technical Note: The single particle soot photometer fails to reliably detect PALAS soot nanoparticles, Atmos. Meas. Tech., 5, 3099-3107, https://doi.org/10.5194/amt-5-3099-2012, 2012.

IPCC: Summary for policymakers, in: Climate Change 2013: The Physical Science Basis. Contribution of Working Group I to the Fifth Assessment Report of the Intergovernmental Panel on Climate Change, edited by: Stocker, T. F., Qin, D., Plattner, G.-K., Tignor, M., Allen, S. K., Boschung, J., Nauels, A., Xia, Y., Bex, V., and Midgley, P. M., Cambridge University Press, Cambridge, United Kingdom and New York, NY, USA, 2013.

Jacobson, M. Z.: Strong radiative heating due to the mixing state of black carbon in atmospheric aerosols, Nature, 409, 695-697, https://doi.org/10.1038/35055518, 2001.

Khalizov, A. F., Xue, H. X., Wang, L., Zheng, J., and Zhang, R. Y.: Enhanced light absorption and scattering by carbon soot aerosol internally mixed with sulfuric acid, J. Phys. Chem. A, 113, 10661074, 2009.

Laborde, M., Mertes, P., Zieger, P., Dommen, J., Baltensperger, U., and Gysel, M.: Sensitivity of the Single Particle Soot Photometer to different black carbon types, Atmos. Meas. Tech., 5, 10311043, https://doi.org/10.5194/amt-5-1031-2012, 2012.

Liu, D., Allan, J., Whitehead, J., Young, D., Flynn, M., Coe, H., McFiggans, G., Fleming, Z. L., and Bandy, B.: Ambient black carbon particle hygroscopic properties controlled by mixing state and composition, Atmos. Chem. Phys., 13, 2015-2029, https://doi.org/10.5194/acp-13-2015-2013, 2013.

Liu, D. T., Whitehead, J., Alfarra, M. R., Reyes-Villegas, E., Spracklen, D. V., Reddington, C. L., Kong, S. F., Williams. P. I., Ting, Y.-C., Haslett, S., Taylor, J. W., Flynn, M. J., Morgan, W. T., McFiggans, G., Coe, H., and Allan, J. D.: Black-carbon absorption enhancement in the atmosphere determined by particle mixing state, Nat. Geosci., 10, 184-188, https://doi.org/10.1038/NGEO2901, 2017.

Ma, Q. X., Wu, Y. F., Zhang, D. Z., Wang, X. J., Xia, Y. J., Liu, X. Y., Tian, P., Han, Z. W., Xia, X. A., Wang, Y., and Zhang, R. J.: Roles of regional transport and heterogeneous reactions in the $\mathrm{PM}_{2.5}$ increase during winter haze episodes in Beijing, Sci. Total Environ., 599-600, 246-253, https://doi.org/10.1016/j.scitotenv.2017.04.193, 2017 a.

Ma, Q. X., Wu, Y. F., Tao, J., Xia, Y. J., Liu, X. Y., Zhang, D. Z., Han, Z. W., Zhang, X. L., and Zhang, R. J.: Variations of chemical composition and source apportionment of $\mathrm{PM}_{2.5}$ during winter haze episodes in Beijing, Aerosol Air Qual. Res., 17, 27912803, https://doi.org/10.4209/aaqr.2017.10.0366, 2017 b.

Maricq, M. M. and Xu, N.: The effective density and fractal dimension of soot particles from premixed flames and motor vehicle exhaust, J. Aerosol Sci., 35, 1251-1274, https://doi.org/10.1016/j.jaerosci.2004.05.002, 2004.

McMeeking, G. R., Good, N., Petters, M. D., McFiggans, G., and Coe, H.: Influences on the fraction of hydrophobic and hydrophilic black carbon in the atmosphere, Atmos. Chem. Phys., 11, 5099-5112, https://doi.org/10.5194/acp-115099-2011, 2011.

Moteki, N. and Kondo, Y.: Effects of mixing state on black carbon measurements by laser-induced incandescence, Aerosol Sci. Technol., 41, 398-417, https://doi.org/10.1080/02786820701199728, 2007.

Ning, Z., Chan, K. L., Wong, K. C., Westerdahl, D., Močnik, G., Zhou, J. H., and Cheung, C. S.: Black carbon mass size distributions of diesel exhaust and urban aerosols measured using differential mobility analyzer in tandem with Aethalometer, Atmos. Environ., 80, 31-40, https://doi.org/10.1016/j.atmosenv.2013.07.037, 2013.

Olfert, J. S., Symonds, J. P. R., and Collings, N.: The effective density and fractal dimension of particles emitted from a light-duty diesel vehicle with a diesel oxidation catalyst, J. Aerosol Sci., 38, 69-82, https://doi.org/10.1016/j.jaerosci.2006.10.002, 2007.

Pagels, J., Khalizov, A. F., McMurry, P. H., and Zhang, R. Y.: Processing of soot by controlled sulphuric acid and water condensation - mass and mobility relationship, Aerosol Sci. Technol., 43 , 629-640, https://doi.org/10.1080/02786820902810685, 2009.

Park, K., Cao, F., Kittelson, D. B., and McMurry, P. H.: Relationship between particle mass and mobility for diesel exhaust particles, Environ. Sci. Technol., 37, 577-583, https://doi.org/10.1021/es025960v, 2003.

Park, K., Kittelson, D. B., and McMurry, P. H.: Structural properties of diesel exhaust particles measured by transmission electron microscopy (TEM): relationships to particle mass and mobility, Aerosol Sci. Technol., 38, 881-889, https://doi.org/10.1080/027868290505189, 2004.

Park, K., Dutcher, D., Emery, M., Pagels, J., Sakurai, H., Scheckman, J., Qian, S., Stolzenburg, M. R., Wang, X., Yang, J., and McMurry, P. H.: Tandem measurements of aerosol properties - a review of mobility techniques with extensions, Aerosol Sci. Technol., 42, 801-816, https://doi.org/10.1080/02786820802339561, 2008.

Peng, J. F., Hu, M., Guo, S., Du, Z. F., Zheng, J., Shang, D. J., Zamora, M. L., Zeng, L. M., Shao, M., Wu, Y.-S., Zheng, J., Wang, Y., Glen, C. R., Collins, D. R., Molina, M. J., and Zhang, R. Y.: Markedly enhanced absorption and direct radiative forcing of black carbon under polluted urban environments, P. Natl. Acad. Sci. USA, 113, 4266-4271, https://doi.org/10.1073/pnas.1602310113, 2016.

Raatikainen, T., Brus, D., Hooda, R. K., Hyvärinen, A.-P., Asmi, E., Sharma, V. P., Arola, A., and Lihavainen, H.: Size-selected black carbon mass distributions and mixing state in polluted and clean environments of northern India, Atmos. Chem. Phys., 17, 371-383, https://doi.org/10.5194/acp-17-371-2017, 2017.

Rissler, J., Nordin, E. Z., Eriksson, A. C., Nilsson, P. T., Frosch, M., Sporre, M. K., Wierzbicka, A., Svenningsson, B., Löndahl, J., Messing, M. E., Sjogren, S., Hemmingsen, J. G., Loft, S., Pagels, J. H., and Swietlicki, E.: Effective density and mixing state of aerosol particles in a near-traffic urban environment, Environ. Sci. Technol., 48, 6300-6308, https://doi.org/10.1021/es5000353, 2014. 
Seinfeld, J. H. and Pandis, S. N.: Atmospheric chemistry and physics, Chapter 9-Dynamics of single aerosol particles, John Wiley \& Sons, Inc., Hoboken, New Jersey, 2006.

Scarnato, B. V., Vahidinia, S., Richard, D. T., and Kirchstetter, T. W.: Effects of internal mixing and aggregate morphology on optical properties of black carbon using a discrete dipole approximation model, Atmos. Chem. Phys., 13, 5089-5101, https://doi.org/10.5194/acp-13-5089-2013, 2013.

Schwarz, J. P., Gao, R. S., Fahey, D. W., Thomson, D. S., Watts, L. A., Wilson, J. C., Reeves, J. M., Darbeheshti, M., Baumgardner, D. G., Kok, G. L., Chung, S. H., Schulz, M., Hendricks, J., Lauer, A., Kärcher, B., Slowik, J. G., Rosenlof, K. H., Thompson, T. L., Langford, A. Q., Loewenstein, M., and Aikin, K. C.: Single-particle measurements of midlatitude black carbon and light-scattering aerosols from the boundary layer to the lower stratosphere, J. Geophys. Res., 111, D16207, https://doi.org/10.1029/2006JD007076, 2006.

Schwarz, J. P., Gao, R. S., Spackman, J. R., Watts, L. A., Thomson, D. S., Fahey, D. W., Ryerson, T. B., Peischl, J., Holloway, J. S., Trainer, M., Frost, G. J., Baynard, T., Lack, D. A., de Gouw, J. A., Warneke, C., and Del Negro, L. A.: Measurement of the mixing state, mass, and optical size of individual black carbon particles in urban and biomass burning emissions, Geophys. Res. Lett., 35, L13810, https://doi.org/10.1029/2008GL033968, 2008.

Shiraiwa, M., Kondo, Y., Iwamoto, T., and Kita, K.: Amplification of light absorption of black carbon by organic coating, Aerosol Sci. Technol., 44, 46-54, https://doi.org/10.1080/02786820903357686, 2010.

Slowik, J. G., Cross, E. S., Han, J. H., Kolucki, J., Davidovits, P., Williams, L. R., Onasch, T. B., Jayne, J. T., Kolb, C. E., and Worsnop, D. R.: Measurements of morphology changes of fractal soot particles using coating and denuding experiments: implications for optical absorption and atmospheric lifetime, Aerosol Sci. Technol., 41, 734-750, https://doi.org/10.1080/02786820701432632, 2007.

Sorensen, C. M.: The mobility of fractal agregates: A review, Aerosol Sci. Technol., 45, 765-779, https://doi.org/10.1080/02786826.2011.560909, 2011.

Taylor, J. W., Allan, J. D., Liu, D., Flynn, M., Weber, R., Zhang, X., Lefer, B. L., Grossberg, N., Flynn, J., and Coe, H.: Assessment of the sensitivity of core/shell parameters derived using the singleparticle soot photometer to density and refractive index, Atmos. Meas. Tech., 8, 1701-1718, https://doi.org/10.5194/amt-8-1701$2015,2015$.
Wang, Q. Y., Huang, R. J., Cao, J. J., Han, Y. M., Wang, G. H., Li, G. H., Wang, Y. C., Dai, W. T., Zhang, R. J., and Zhou, Y. Q.: Mixing state of black carbon aerosol in a heavily polluted urban area of China: implications for light absorption enhancement, Aerosol Sci. Technol., 48, 689-697, https://doi.org/10.1080/02786826.2014.917758, 2014.

Wang, Y. Y., Liu, F. S., He, C. L., Bi, L., Cheng, T. H., Wang, Z. L., Zhang, H., Zhang, X. Y., Shi, Z. B., and Li, W. J.: Fractal dimensions and mixing structrures of soot particles during atmospheric processing, Environ. Sci. Tech. Lett., 4, 487-493, https://doi.org/10.1021/acs.estlett.7b00418, 2017.

Wu, Y., Wang, X., Tao, J., Huang, R., Tian, P., Cao, J., Zhang, L., Ho, K.-F., Han, Z., and Zhang, R.: Size distribution and source of black carbon aerosol in urban Beijing during winter haze episodes, Atmos. Chem. Phys., 17, 7965-7975, https://doi.org/10.5194/acp-17-7965-2017, 2017.

Wu, Y. F., Zhang, R. J., Tian, P., Tao, J., Hsu, S.-C., Yan, P., Wang, Q. Y., Cao, J. J., Zhang, X. L., and Xia, X. A.: Effect of ambient humidity on the light absorption amplification of black carbon in Beijing during January 2013, Atmos. Environ., 124, 217-223, https://doi.org/10.1016/j.atmosenv.2015.04.041, 2016.

Zhang, R., Jing, J., Tao, J., Hsu, S.-C., Wang, G., Cao, J., Lee, C. S. L., Zhu, L., Chen, Z., Zhao, Y., and Shen, Z.: Chemical characterization and source apportionment of $\mathrm{PM}_{2.5}$ in Beijing: seasonal perspective, Atmos. Chem. Phys., 13, 7053-7074, https://doi.org/10.5194/acp-13-7053-2013, 2013.

Zhang, R. Y., Khalizov, A. F., Pagels, J., Zhang, D., Xue, H., Chen, J., and McMurry, P. H.: Variability in morphology, hygroscopic and optical properties of soot aerosols during internal mixing in the atmosphere, P. Natl. Acad. Sci. USA, 105, 10291-10296, https://doi.org/10.1073/pnas.0804860105, 2008.

Zhang, Y., Zhang, Q., Cheng, Y., Su, H., Kecorius, S., Wang, Z., Wu, Z., Hu, M., Zhu, T., Wiedensohler, A., and He, K.: Measuring the morphology and density of internally mixed black carbon with SP2 and VTDMA: new insight into the absorption enhancement of black carbon in the atmosphere, Atmos. Meas. Tech., 9, 1833-1843, https://doi.org/10.5194/amt-9-1833-2016, 2016. 